\title{
Can Renewable Energy Sustain an Age of Cheap Energy?
}

\author{
Hazuki Ishida*
}

Faculty of Symbiotic Systems Science, Fukushima University, 1, Kanayagawa, Fukushima, 960 1296, Japan

\begin{abstract}
Utilizing renewable energy depends more or less upon non-renewable energy sources (mainly fossil fuels), and which implies that a continuous rise in energy prices is inevitable without technological progress in saving fossil fuel use. Using a simple Hotelling model of optimal resource extraction, this paper explores the conditions under which the continuous price rise of renewable energy is restrained in the presence of technological progress in harnessing renewable energy. The results show that to sustain the age of cheap energy, the growth rate of technology in harnessing renewable energy has to be larger than the discount rate. Even if the rate of the technological progress is faster than the discount rate, the energy price may continue to rise until the conventional system of energy generation from fossil fuels is obsolete.
\end{abstract}

Keywords: Renewable energy, fossil fuels, technological progress, discount rate, Hotelling model.

\section{INTRODUCTION}

As Georgescu-Roegen pointed out, there is an intrinsic difference between non-renewable (stock-type) energy sources (mainly fossil fuels) and renewable energy sources (direct and indirect forms of solar energy, geothermal energy): a stock-type resource can be exploited at a virtually unlimited rate, whereas we cannot take full control of the rate of energy flow from renewable sources [1]. So it is not surprising that fossil fuels and renewables are primarily associated with industry and agriculture, respectively. Fossil fuels also have other advantages over renewables: high energy density, high energy return on energy invested (ERoEl), high power density, low cost, ease of combustion, and high flexibility in providing several forms of secondary energy [2-4]. In particular, fossil fuels exert a strong influence on the transportation sector. In very few countries in the world do fossil fuels account for less than $97 \%$ of transportation fuel use [5]. This is because fossil fuels are easily transported, mainly because of their high energy density per mass/volume, and are easy to handle and burn, which means that heavy equipment need not be installed in transportation containers.

Although uranium ore deposits are terrestrial stock like fossil fuels, there are some essential differences between these two types of energy sources as follows. First, unlike with fossil fuels, uranium ore is not a low entropy resource, so it needs to be enriched to increase the exergy content by using other low entropy resources such as fossil fuels. Second, uranium ore cannot be burned as easily as fossil fuels; highly

*Address correspondence to this author at the Faculty of Symbiotic Systems Science, Fukushima University, 1, Kanayagawa, Fukushima, 960 1296, Japan; Tel/Fax: +81 (0)24 548 8439; E-mail: e059@ipc.fukushima-u.ac.jp complex systems are needed to harness nuclear energy safely. Finally, nuclear energy can only supply electricity while fossil fuels can be used for everything from transportation fuel to chemical feedstock. In any case, the fact remains that uranium is an exhaustible energy source like fossil fuels. According to Leeuwin and Smith, there is far too little uranium at a sufficient grade to sustain a nuclear era for more than several years [6].

In the light of overwhelming advantages for fossil fuels, it is quite misleading to believe that we can easily move away from an exhaustible resource-based society toward a society based on renewable energy flows which are inherently intermittent and have low power density (two to three orders of magnitude lower than typical power densities of fossil fuels [4]). There are two ways to obtain stable energy from renewables: namely, backup through conventional systems based on fossil fuels (e.g. coal-fired plants to back up windmills), or energy storage. In the former case, the relationship between renewables and fossil fuels is not substitutive, rather complementary. In the latter case, we have to develop inexpensive measures to store very large quantities of energy flow from renewable sources. The most conventional way to store the energy is to pump water up into dams. Unfortunately, it seems to be difficult to obtain a satisfactory number of sites well suited to the construction of many new dams with sufficient storage capacity [2].

Another traditional way to store renewable energy is to harvest and store biomass (solid or liquid). However, as the average energy production density of phytomass is very low [7], heavy dependence upon biomass energy to feed a mass-consumption society may lead to fierce competition over finite fertile lands for the production of food. Moreover, conventional agriculture has only come about with huge inputs of fossil fuels [8]. 
Other ways to store energy (hydrogen, compressed air, vanadium batteries, flywheels, etc.) have so far no prospects of supplying massive energy to our society without the help of fossil fuels [2]. In any case, mass adoption of renewables would necessitate a large-scale infrastructure reconstruction to bridge power density gaps between fossil fuels and renewables [4]. Again, as Ferguson pointed out, the whole project of producing a power-generating system and storage capacity cannot be implemented without fossil fuels [9]. Above all, the more strongly we harness renewable energies, the more fossil fuels we have to use.

Thus far, some economists have discussed the optimal extraction path of natural resources by incorporating a backstop technology that substitutes unconventional resources for conventional nonrenewables [10-13]. Although these findings are suggestive, it is not appropriate to use these models for investigating the economics of renewable energy whose use requires fossil fuels. Intuitively, in the absence of technological improvements in reducing fossil fuel use in harnessing renewable energy, the basic Hotelling's rule predicts that the price of renewable energy should continue to grow [14].

This paper explores the conditions under which a continuous price rise of renewable energy is restrained in the presence of technological progress in harnessing renewable energy. The remainder of the paper is organized as follows. Section 2 develops the model. Section 3 concludes.

\section{THE MODEL}

Consider the problem to derive the social optimal path of extraction of non-renewables. Let $E_{t}$ denote energy consumption at $t$ and $U($.$) an increasing$ concave utility function (known as Gossen's first law) over energy consumption for a representative consumer. Assume that energy is derived from nonrenewables $\left(q_{t}\right)$ and/or renewables $\left(r_{t}\right)$. As already mentioned above, renewable energy is not itself stable and high grade energy, so harnessing renewable energy needs more or less exploitation of nonrenewables despite the annual flows of renewable energies is nearly four orders magnitude greater than the annual fossil fuel consumption [4]. The change rate in stock of non-renewables $R_{t}$ is expressed by:

$\dot{R}_{t}=-q_{t}-m_{t} \varnothing\left(r_{t}\right)$

where a dot denotes time derivative, $m_{t}$ denotes exogenous technological progress taking the form:
$m_{t}=e^{-\Gamma t}$

where $\Gamma$ is a positive constant. The function $\varnothing($. represents the consumption of non-renewables in the renewable energy sector without technological progress. Since the more efficient energy sources tend to be developed in first, the more renewable energy we try to harness, the faster marginal cost of harnessing undeveloped renewable energy will rise. Therefore, it is reasonable to suppose $\varnothing^{\prime}()>$.0 , and $\varnothing^{\prime \prime}$ (.) $>0$.

Then, energy available to the representative consumer at time $t$ is:

$E_{t}=q_{t}+r_{t}$.

Assume that $q_{0}>0\left(E_{0}>r_{0}\right)$, namely, part of energy is directory derived from non-renewable sources at the initial time. Without any externalities, the competitive equilibrium equals to the following social planner's problem to maximize social welfare [15]:

$\max \int_{0}^{\infty} U\left(E_{t}\right) e^{-\rho t} d t$

subject to equation (1) and equation (3), and $\rho$ is the discount rate. The corresponding current value Hamiltonian [16] is:

$H=U\left(E_{t}\right)-\mu_{t}\left(q_{t}+m_{t} \varnothing\left(r_{t}\right)\right)$

where $\mu$ is the shadow value of the stock of nonrenewables. In the case of $q_{t}>0$ and $r_{t}>0$, the first-order conditions are as followings [16]:

$$
\begin{aligned}
& \frac{\partial H}{\partial q_{t}}=U^{\prime}\left(E_{t}\right)-\mu_{t}=0 \\
& \frac{\partial H}{\partial r_{t}}=U^{\prime}\left(E_{t}\right)-\mu_{t} m_{t} \varnothing^{\prime}\left(r_{t}\right)=0 \\
& -\frac{\partial H}{\partial R_{t}}=0=\dot{\mu}_{t}-\rho \mu_{t} .
\end{aligned}
$$

Using equation (6) and equation (8) together, we obtain:

$\frac{\dot{U}^{\prime}}{U^{\prime}}=\rho$

In the case of competitive equilibrium, the marginal utility of energy equals the energy price. Hence, equation (9) implies that the energy price will rise at the discount rate. On the other hand, taking the logarithm and time derivative of both sides of equation (7) yields: 
$\frac{\dot{U}^{\prime}}{U^{\prime}}=\frac{\dot{\mu}_{t}}{\mu_{t}}+\frac{\dot{m}_{t}}{m_{t}}+\frac{\dot{\varnothing}^{\prime}}{\varnothing^{\prime}}$

Combining equation (9) and equation (10) yields:

$\frac{\dot{\varnothing}^{\prime}}{\varnothing^{\prime}}=-\frac{\dot{m}_{t}}{m_{t}}=\Gamma$.

From equation (3), the extraction rate of nonrenewables is:

$q_{t}=E_{t}-r_{t}$.

Note that $q_{t}$ will eventually fall to zero, because equation (9) implies that energy consumption will monotonically decline, while equation (11) implies that the harnessing of renewable energy will monotonically rise. Then, let $T_{p}$ denote the time at which $q_{t}$ is equal to zero. As the value of $q_{t}$ cannot be negative, $q_{t}=0$ and $E_{t}=r_{t}$ for all $t>T_{p}$. Since equation (6) is not available after $t=T_{p}$, the time path of energy consumption for $t>T_{p}$ is determined by equation (7) and equation (8), namely,

$\frac{\dot{\varnothing}^{\prime}}{\varnothing^{\prime}}-\frac{\dot{U}^{\prime}}{U^{\prime}}=\Gamma-\rho$

From the definition of the shapes of $U($.$) and \varnothing($.$) ,$

$\operatorname{sign}\left[\frac{\dot{E}_{t}}{E_{t}}\right]=\operatorname{sign}\left[\frac{\dot{r}_{t}}{r_{t}}\right]=\operatorname{sign}\left[\frac{\dot{\varnothing}^{\prime}}{\varnothing^{\prime}}\right]=-\operatorname{sign}\left[\frac{\dot{U}^{\prime}}{U^{\prime}}\right]$.

From equation (13) and equation (14), we can evaluate the direction of change in the energy price for $\downarrow T_{p}$ :

$\operatorname{sign}\left[\frac{\dot{U}^{\prime}}{U^{\prime}}\right]=-\operatorname{sign}[\Gamma-\rho]$.

From equation (9), the price of energy continues to rise at the discount rate $(\rho)$ during $0<t<T_{p}$ regardless of the growth rate of technology $(\Gamma)$. This result is not surprising because the marginal production of energy in equilibrium is determined by the efficiency in the use of non-renewables. On the other hand, equation (15) implies that the energy price will begin to decline at $T_{p}$ if $\Gamma>\rho$. Note that the technological progress in harnessing renewable energy may not necessarily lead to a decline in the energy price unless $\Gamma$ is beyond a certain value (namely, discount rate). Unfortunately, it is difficult to observe quantitatively the long-term trend of technological progress. To aid approximation, we note, for example, that the cost of wind-generated electricity fell at an average rate of 8 percent per year from 1980 to 2005. However, the decline in the cost is projected to be slower from 2005 to 2020, say, 4 percent per year on average [17]. Similarly, although the cost of photovoltaic modules has fallen substantially in the last two decades, this downward trend now seems to have ceased [2]. Besides, IEA predicts that fossil fuel combustion may remain the dominant source of primary energy generation for at least several decades [18]. If that is true, the long-term decrease in energy price will not begin for at least several decades.

\section{CONCLUSION}

Using a simple Hotelling model of optimal resource extraction, this paper explores the conditions under which the continuous price rise of renewable energy is restrained in the presence of technological progress in harnessing renewable energy, considering the fact that the use of non-renewables such as fossil fuels is indispensable to harnessing renewable energy to feed a mass-consumption society.

The conclusions of this paper are as followings. First, to sustain an age of cheap energy, the growth rate of technology in harnessing renewable energy has to be larger than a certain level (= discount rate). Second, even if the rate of the technological progress is faster than the discount rate, the energy price may continue to rise until the conventional system of energy generation based on non-renewables is obsolete.

This paper does not deny the possibility of a society being nearly independent of fossil fuels, as such is the case for all preindustrial small-sized societies. Instead, this paper is skeptical about the idea that a large amount of cheap energy can be supplied by renewable energy sources in the near future.

\section{REFERENCES}

[1] Gerogescu-Roegen N. The entropy law and the economic process. Cambridge: Harvard University Press 1971.

[2] Trainer T. Renewable energy cannot sustain a consumer society. London: Springer 2007.

[3] Hall C, Balogh S, Murphy D. What is the minimum EROI that a sustainable society must have? Energies 2009; 2: 25-47. http://dx.doi.org/10.3390/en20100025

[4] Smil V. Energy transitions: history, requirements, prospects. Santa Barbara: Praeger 2010.

[5] Fulton L. Reducing oil consumption in transporting: combining three approaches. IEA/EET Working Paper 2004 1: 1-24.

[6] van Leeuwen J, Smith P. Nuclear power: the energy balance. Netherlands: Chaam 2005.

[7] Smil V. Energy in nature and society. Cambridge: The Mit Press 2008. 
[8] Patzek T. Can the earth deliver the biomass-for-fuel we demand? In Pimentel D, Ed.Biofuels, solar and wind as renewable energy systems. Berlin: Springer 2008.

[9] Ferguson A. Wind power: benefits and limitations. In Pimentel D, Ed. Biofuels, solar and wind as renewable energy systems. Berlin: Springer 2008.

[10] Dasgupta PS, Heal GM. Economic theory and exhaustible resources. Cambridge: Cambridge University Press 1979.

[11] Pearce DW, Turner RK. Economics of natural resources and the environment. London: Harvester Wheatsheaf 1990.

[12] Hartwick JM, Olewiler ND. The economics of natural resource use. Boston: Addison-Wesley 1998.

[13] Tsur Y, Aemel A. Optimal transition to backstop substitutes for non-renewable resources. J Econ Dyn Control 2003; 27: 551-72. http://dx.doi.org/10.1016/S0165-1889(01)00061-6
[14] Hotelling $\mathrm{H}$. The economics of exhaustible resources. J Polit Econ 1931; 39: 137-75. http://dx.doi.org/10.1086/254195

[15] Hanley N, Shogren JF, White B. Environmental economics. New York: Macmillan Press 1997.

[16] Chiang AC. Elements of dynamic optimization. New York: McGraw-Hill 1992.

[17] Mathew S. Wind energy. Berlin-Heidelberg: Springer 2006.

[18] IEA. World Energy Outlook. International Energy Agency 2008. 